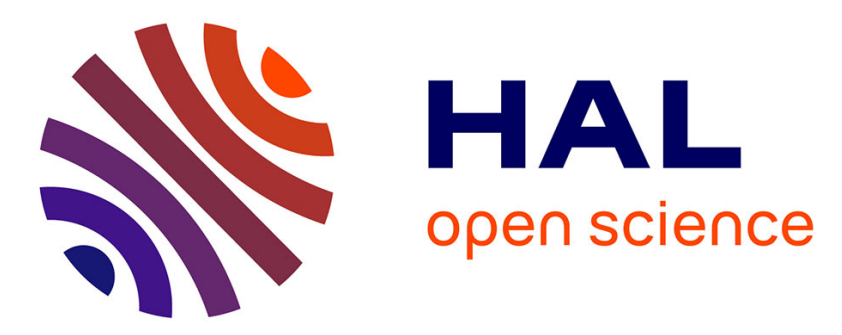

\title{
Avoidant social style among wild crested macaque males (Macaca nigra) in Tangkoko Nature Reserve, Sulawesi, Indonesia
}

Maura Tyrrell, Carol M Berman, Julie Duboscq, Muhammad Agil, Try Sutrisno, Antje Engelhardt

\section{To cite this version:}

Maura Tyrrell, Carol M Berman, Julie Duboscq, Muhammad Agil, Try Sutrisno, et al.. Avoidant social style among wild crested macaque males (Macaca nigra) in Tangkoko Nature Reserve, Sulawesi, Indonesia. Behaviour, 2020, 157 (5), pp.451-491. 10.1163/1568539X-bja10009 . hal-02909359

\section{HAL Id: hal-02909359 \\ https://hal.science/hal-02909359}

Submitted on 14 Oct 2020

HAL is a multi-disciplinary open access archive for the deposit and dissemination of scientific research documents, whether they are published or not. The documents may come from teaching and research institutions in France or abroad, or from public or private research centers.
L'archive ouverte pluridisciplinaire HAL, est destinée au dépôt et à la diffusion de documents scientifiques de niveau recherche, publiés ou non, émanant des établissements d'enseignement et de recherche français ou étrangers, des laboratoires publics ou privés. 


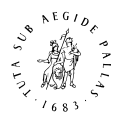

B R I L L

Behaviour 0 (2020) 1-41

Behaviour

brill.com/beh

\section{Avoidant social style among wild crested macaque} males (Macaca nigra) in Tangkoko Nature Reserve, Sulawesi, Indonesia

\section{Maura Tyrrell ${ }^{\mathrm{a}, *}$, Carol M. Berman ${ }^{\mathrm{a}, \mathrm{b}}$, Julie Duboscq ${ }^{\mathrm{c}}$, Muhammad Agil $^{\mathrm{d}}$, Try Sutrisno $^{\mathrm{d}}$ and Antje Engelhardt ${ }^{\mathrm{e}}$}

${ }^{\text {a }}$ Graduate Program in Evolution, Ecology and Behavior, University at Buffalo, Buffalo, NY, USA

${ }^{\mathrm{b}}$ Department of Anthropology, University at Buffalo, Buffalo, NY, USA

${ }^{c}$ UMR 7206 Eco-anthropologie, CNRS — MNHN — Paris Diderot, Musée de l'Homme, Paris, France

${ }^{\mathrm{d}}$ Faculty of Veterinary Medicine, Bogor Agricultural University, Bogor, Indonesia

${ }^{\mathrm{e}}$ School of Natural Sciences and Psychology, Liverpool John Moores University, Liverpool, UK

*Corresponding author's e-mail address: mauratyr@buffalo.edu

Received 1 October 2019; initial decision 17 November 2019; revised 28 March 2020; accepted 6 April 2020

\section{Abstract}

Although it is well established that female crested macaques (Macaca nigra) display very tolerant social styles, less is known about the extent to which crested macaque males can be characterized by the social style concept. We examined core social style traits and other measures of social interactions in three groups of wild crested macaque males in Tangkoko Reserve, Indonesia. Comparisons with males of other macaque species suggest that they display a mixture of tolerant and despotic indicators, a pattern inconsistent with tolerant, despotic or uniformly intermediate designations. Their apparent avoidance of affiliative interactions and reconciliation involving contact suggest that their relationships also contrast with the typically affiliative and relaxed social style of female crested macaques. Rather than labeling them as distinctly tolerant or despotic, we describe the social style of crested males as 'avoidant', which may reflect tense relationships due to high levels of risky reproductive competition. 


\section{Introduction}

\subsection{Social style}

Primate social structure varies markedly among group-living species, and the concept of social style has been used to describe aspects of that variation. The social style concept is based on the observation that several aspects of social structure, including dominance asymmetry, intensity of aggressive interactions, responses to aggression, kin preferences- and conflict management strategies, appear to co-vary with one another among species (Thierry, 2000, 2007). Among macaques, social styles are hypothesized to vary on a four-grade scale from extremely despotic to extremely tolerant. Extremely despotic species (grade 1) like Japanese (Macaca fuscata) and rhesus macaques (Macaca mulatta) typically exhibit intense unidirectional aggression, strong dominance asymmetry, strong preferences for kin, and low proportions of reconciled conflicts (Thierry, 2000, 2007). On the opposite end of the scale, extremely tolerant species (grade 4) like moor macaques (Macaca maura) and Tonkean macaques (Macaca tonkeana) show less intense aggression, bidirectional conflicts, weak dominance asymmetry, less intense kin preferences, and high proportions of reconciled conflicts (Thierry, 2000, 2007). In addition, in despotic societies the silent-bared teeth display, a facial expression in which the teeth are exposed by the vertical retraction of the lips, is a unidirectional submission signal consistently given by a subordinate to a dominant individual (de Waal \& Luttrell, 1985), whereas in grade 4 species, the silent-bared teeth display is a bidirectional signal of friendly intention used by both dominants and subordinates that facilitates friendly interactions (Dixson, 1977; Duboscq et al., 2013; Thierry et al., 1989, 2000).

Studies of social style in macaques have focused primarily on females, because females form the permanent core of macaque groups, and because most early studies related to social style were done in captive groups that often contained only a few fully adult males (e.g., Thierry, 1985; De Waal \& Ren, 1988; De Waal \& Luttrell, 1989; Butovskaya, 1993; Petit et al., 1997; Demaria \& Thierry, 2001). Thus male-male interactions were often omitted or lumped in with female data. This left open the question of whether the social style framework can be used to characterize macaque male-male relationships as despotic or tolerant as well. Many early researchers assumed that intense competition over fertilizations among primate males should inhibit social bonding between males and traits associated with a tolerant social 6 
style in favor of aggression and overt competition (van Hooff \& van Schaik, 1992, 1994; van Schaik, 1996; van Hooff, 2000), thus limiting males to despotic social styles, if any. Additionally, male-male relationships may be expected to be weaker than female-female relationships in macaques due to their social organization; females are philopatric and males disperse from their natal groups. As a result, adult males are less likely to be related, and hence closely bonded, to other group males than are females, especially females belonging to the same matriline. Nevertheless, affiliative and cooperative relationships between males have been described in a number primate species, including macaques (Hill, 1994; van Hooff \& van Schaik, 1994), suggesting that they may display a range of social styles. However, detailed studies of core social style traits for male-male interactions have been done for relatively few species (M. arctoides: Richter et al., 2009; M. maura: Riley et al., 2014; M. sylvanus: Preuschoft et al., 1998; M. thibetana: Berman et al., 2007; M. radiata: Cooper et al., 2007; M. assamensis: Cooper \& Bernstein, 2008); hence it is as yet unclear whether primate male social style traits covary as predicted by the social style concept.

It also remains unclear whether males tend to show similar or sharply different social styles as their female conspecifics. Given that male and female infants of many primate species, including macaques, experience similar treatment by mothers, and that both sexes conform to particular speciestypical patterns of interaction that may be partly constrained by inherent traits (i.e., social reaction norms), it may seem reasonable at first to hypothesize that they may display similar social styles. However, males and females are also subject to widely different selective pressures within groups; whereas female reproductive success is limited primarily by resource distribution, male reproductive success is limited by fertilization (Emlen \& Oring, 1977). Thus, social styles may be predicted to differ between the sexes. Indeed, recent studies on macaques have shown that male-male social relationships may differ markedly from those of female conspecifics. For example, stumptail macaque males show more despotic tendencies than their female counterparts, including higher proportions of intense aggression and lower proportions of counteraggression (Richter et al., 2009). In contrast, male Tibetan macaques (Berman et al., 2004, 2007), Barbary macaques (Preuschoft et al., 1998), and Assamese macaques (Cooper \& Bernstein, 2002, 2008; Schulke et al., 2010; Ostner \& Schulke, 2014) all have relatively more tolerant social relationships in comparison to their female counterparts. Finally, 
moor macaque males appear to be similar to extremely tolerant females in their low rates of aggression, low proportions of intense aggression, but more similar to grade 2 and 3 macaques' proportions of counteraggression (Riley et al., 2014). Additionally, a study by Palagi et al. (2014) on Tonkean macaques reports sex differences in patterns of consolation (affiliation between victims and third party), highlighting the nuances between male-male and female-female relationships. Thus the extent to which male relationships resemble those of female conspecifics and the factors that may lead the sexes to vary are also still unclear. Here we attempt to fill some of these gaps by examining social relationships among adult male crested macaques (Macaca nigra) with an emphasis on core social style traits. By examining core social style traits separately in males and females, we aim to get a better overall understanding of differences in male and female social styles.

\subsection{Crested macaques}

Crested macaques are one of seven macaque species endemic to Sulawesi, Indonesia (Fooden 1969). While females remain in their natal groups for life forming matrilines, males disperse after reaching sexual maturity and may immigrate into other groups several times throughout their lifetime (Reed et al., 1997; Marty et al., 2017). Wild (Duboscq et al., 2013) and captive crested macaque females (Petit \& Thierry, 1994; Petit et al., 1997) have been characterized as extremely tolerant and placed in grade 4 of the social style scale (Thierry, 2007). Duboscq and colleagues (2013) found that wild crested macaque females have frequent low intensity aggression, high proportions of bidirectional conflicts, moderate dominance asymmetry and high conciliatory tendencies compared with other female macaques. When approached nonagonistically by other females, they are more likely to respond with affiliation than agonism (Duboscq et al., 2013), after which they often remain in close proximity for up to several minutes (Tyrrell, personal observation). Finally, silent bared-teeth displays are friendly facial expressions distributed equally to dominants and subordinates. Male crested macaque relationships have not been as extensively examined as female crested macaque relationships. Captive groups have contained too few males to examine male-male relationships separately from females (Petit \& Thierry, 1994; Petit et al., 1997). Reed et al. (1997) were the first to focus on wild crested macaque males, characterizing them as hierarchical and antagonistic. Despite this assessment, other researchers have reported affiliative behaviour patterns 
indicative of a degree of tolerance, including post conflict reconciliation and ritualized greetings in which males exchange affiliative gestures like mounting, genital-grasping, or mock biting (Dixson, 1977; Petit \& Thierry, 1994). These greetings may be similar to those observed in baboons (Smuts \& Watanabe, 1990; Whitham \& Maestripieri, 2003) and bonnet macaques which are hypothesized to show tolerant styles (Sugiyama, 1971; Silk, 1994). Thus male-male relationships appear to be more complex than originally thought.

\subsection{Socioecological and phylogenetic models}

Competing hypothetical explanations for covariation in aspects of social style across species have been based on socioecological factors and phylogenetic/structural considerations (socioecological: Wrangham, 1980; van Schaik, 1989; Koenig et al., 2013; Isbell, 2017; phylogenetic/structural: Matsumura, 1999; Thierry et al., 2000, 2008; Thierry, 2004; Kamilar \& Cooper, 2015). The most current socioecological model (Sterck et al., 1997) focuses on females and is based on the assumption that females' needs for resources and safety influence their distribution and the nature of their relationships to one another. Specifically, females form groups when doing so facilitates gaining access to food and protection from predators and/or infanticidal males. Once females coalesce into permanent and cohesive groups, food abundance and distribution are hypothesized to determine the types of competitive regimes females face (i.e., the level competition for food resources within and between groups). These competitive regimes in turn lead to variable patterns of dominance asymmetry that give rise ultimately to their social styles and variable levels of kin bias. In female philopatric species, including macaques, high within group competition is hypothesized to lead to despotism. However, despotic tendencies will be moderated when high within group competition is accompanied by high between group competition. Although there is evidence supporting the idea that food distribution and the resulting feeding competition influence female social relationships 31 in some ways, the socioecological model's predictions related to dominance, 32 coalitions and kinship, have not been consistently supported (Matsumura, 33 1999; Menard, 2004; Thierry, 2008; Clutton-Brock \& Janson, 2012; Koenig 34 et al., 2013; Balasubramaniam et al., 2014).

The socioecological model's predictions for male-male relationships 36 posit that the nature of male-male relationships depends on the level of 
competition between males, which is influenced primarily by the distribution of females and the dynamics of female relationships (Emlen \& Oring, 1977; van Hooff \& van Schaik, 1994; van Schaik, 1996; Kappeler \& van Schaik, 2002). When females form coherent groups from which single males cannot exclude other males, males must compete with one another over access to fertile females, a resource that cannot be shared. When access to fertile females is monopolisable within a group, high contest competition, in which aggression or displacements by dominants reduces other individuals' access to resources (Janson \& van Schaik, 1988; van Schaik \& van Noordwijk, 1988), is hypothesized to interfere with the formation of affiliative and cooperative relationships between males (Van Hooff \& Van Schaik, 1992, 1994). As such, high contest competition among males should result in high reproductive skew in which the most dominant males copulate most with fertile females (van Hooff, 2000). When females are not monopolisable, several males may compete by sperm competition rather than contest competition (Harcourt et al., 1981, Harvey et al., 1995), reducing constraints on affiliation and cooperation. Like females, males subject to high within group competition (and high reproductive skew) are hypothesized to show greater tolerance to one another when they also experience high levels of between-group competition (Van Schaik, 1996;Van Hooff, 2000). Tolerance in the form of reduced aggression toward subordinates by dominant individuals during times of competition over resources may also represent a behavioural mechanism to prevent escalated aggressive conflicts (e.g., Barbary macaques: Preuschoft et al., 1998). In crested macaques, mating success and paternity are highly skewed in favour of the highest ranking males (Engelhardt et al., 2017). This, along with a high degree of sexual dimorphism and vocal signals of dominance (Neumann et al., 2010), suggest strong contest competition between males within groups. Immigrating males are often met with fierce resistance from resident males (Marty et al., 2017), and frequent intergroup encounters also occur (0.8/day) (Martínez Íñigo, 2018), suggesting high levels of between-group competition.

In contrast to the socioecological model's claim that competitive regimes and social relationships are shaped primarily by ecological determinants, other more recent models emphasize the importance of evolutionary history and structural linkages in shaping primate social systems. Although socioecological factors may have shaped primate social structure in the distant past, phylogenetic analyses suggest that current variation in female relationships 
may be better explained by phylogenetic relationships than by adaptation to current socioecological conditions (Menard, 2004; Thierry, 2008; CluttonBrock \& Janson, 2012; Kamilar \& Cooper, 2015). Thierry's structural model in particular focuses on social style traits and purports that they are inherent characteristics that are structurally inter-related, and as a result co-evolve (and covary) with one another across species (Thierry, 2004, 2007, 2013). There is increasing evidence that related species have similar social styles, despite differences in feeding ecology or ecological conditions (Di Fiore \& Rendall, 1994; Thierry et al., 2000, 2008; Thierry, 2007, 2008; Balasubramaniam et al., 2012, 2018) suggesting that phylogenetic history is an important factor in the evolution of primate social systems, particularly for Old World Monkeys. Although differences between groups of the same species have been reported, these differences are considerably smaller relative to differences across species (Thierry et al., 2008). Nevertheless, some studies show intraspecific variability in social style traits across groups (e.g., Zhang \& Watanabe, 2014) or over time (Berman \& Thierry, 2010), suggesting some flexibility related to current conditions, including group size (Balasubramaniam et al., 2011), socionomic sex ratios and intergroup competition (Majolo et al., 2009; Horiuchi et al., 2007).

\subsection{Covariation of social style traits}

A common approach to empirically distinguish between the structural and socioecological models is through the concept of covariation of social style traits vs. the influence of external factors. The structural model explicitly predicts the covariation of traits, given its emphasis on the inherent linkage of social style traits. While the socioecological framework predicts the clustering of social style traits to some extent (Sterck et al., 1997; Koenig et al., 2013), it does not necessarily predict structural linkages or tight covariation among them. Rather it predicts variation of social style traits with factors expected to influence competitive regimes, e.g., group size. So far, 22 the concept of covariation of social style traits has received some empirical support, but the extent to which traits actually covary is unclear. Assigning females of macaque species to the grades on the extreme ends of the scale (1 32 33 and 4) has been straightforward, as characteristics fit the predicted patterns with little overlap. However, placing species into the intermediate grades (2 and 3) has been more problematic. For example, Balasubramaniam et 36 al. (2012) found that among female macaques, counteraggression behaved 
dichotomously rather than continuously along the scale, and some species assigned to an intermediate grade showed a mix of tolerant and despotic characteristics that did not appear to covary systematically. Moreover, some traits including those related to grooming kin bias and social network modularity (Berman \& Thierry, 2010; Sueur et al., 2011; Balasubramaniam et al., 2018) were strongly related to group size. In a recent review, Balasubramaniam and colleagues (2020) suggested that such mixed results for covariation and evidence of flexibility with external conditions is consistent with the idea that covariation among social style traits was present in the distant evolutionary past of the genus, but that it has been subsequently modified by semi-independent responses to variation in current conditions.

\subsection{Aim and predictions}

Here we aim to characterize the social style of wild crested macaque males by examining several core indicators, including aggression intensity, counteraggression, dominance asymmetry, conciliatory tendency, outcomes of nonagonistic approaches and the silent bared-teeth display. These indicators will be compared (1) with available published data for males of other macaque species, (2) with female crested macaques, using data from Duboscq and colleagues (2013) and (3) among males within the three study groups. Additional behavioural measures, including rates of nonagonistic approaches, affiliation and aggression, will be compared to female crested macaques to supplement descriptions of relationships.

If males exhibit a tolerant social style, we predict that they will display relatively low proportions of aggressive interactions involving biting, high proportions of counteraggression, low hierarchical steepness, high conciliatory tendencies, high proportions of affiliative responses to nonagonistic approaches and bidirectional silent bared-teeth displays.

If crested macaque males exhibit a despotic social style, we predict that they will display relatively high proportions of aggressive interactions involving biting, low proportions of counteraggression, high hierarchical steepness, low conciliatory tendencies, low proportions of affiliative responses to nonagonistic approaches and unidirectional silent bared-teeth displays.

If the male social style traits listed above covary closely with one another, we predict that, relative to other macaque males, all traits will consistently indicate the same social style, e.g., extremely despotic, extremely tolerant or consistently intermediate. 
If crested macaque male social style is similar to that of tolerant crested females, there should be no significant differences between their measures on these traits and those of females. If their relationships are similarly friendly and relaxed as those of females, we predict similarly high rates of affiliation and nonagonistic approaches, and low rates of aggression.

If social style traits are primarily inherent species-characteristics rather than variable responses to current circumstances (e.g., variation in group size, male immigration rates, intensities of tourism/crop-guarding, see Methods below), we predict that male social style traits listed above should not differ significantly between study groups. Significant variation between groups in social style traits and other types of interaction would suggest responses to current conditions, consistent with a socioecological explanation. 2 3 4 5 6 7 8 9 10 11 12

Our methods follow the research guidelines of the United States and Indonesian governments and institutions, and the guidelines of ASAB for the treatment of animals in behavioural research and teaching. Our data collection protocol was approved by the University at Buffalo's IACUC committee (No. ANT04074N).

Data collection took place at Tangkoko Nature Reserve in North Sulawesi, Indonesia $\left(1^{\circ} 33^{\prime} \mathrm{N}, 125^{\circ} 10^{\prime} \mathrm{E}\right)$ from March 2016-February 2017, as part of a long-term project, the Macaca Nigra Project (MNP). The reserve is classified as lowland rainforest with seasonal changes in rainfall, composed of primary and secondary forest with areas of regenerating gardens (O'Brien \& Kinnaird, 1997). The Macaca Nigra Project (www.macaca-nigra.org) established the field site within the Tangkoko Reserve in Sulawesi in 2006. Currently three groups are fully habituated and regularly followed on foot by MNP staff and researchers. Two of the groups (R2 and R1) are also subjected to tourism and crop guarding, while the third (PB1) is not.

We observed the three wild, unprovisioned study groups throughout the duration of the project. Group R1 had a total of approximately 110 individuals, including 10-13 adult males and 33 adult females, R2 had a total of about 70 individuals, including 6 adult males and 27 adult females, and PB1 had a total of about 78 individuals, including 7 adult males and 26 adult females. Kinship among adult males was unknown. All adult individuals were 
identified by scars, broken or missing fingers, facial features and/or the shape of the anogenital region.

\subsection{Data collection}

MT, TS and three other field assistants followed the study groups from dawn to dusk (ca. 0500 h to 1730 h, WITA) daily, from March 2016 to February 2017. We collected a total of 2595 hours of data from 28 adult males (mean: $92.7 \mathrm{~h} / \mathrm{male}$; range: $7.4-150.3 \mathrm{~h}$ ), using focal animal sampling (Altmann, 1974). At the start of the study, focal males included all adult, non-natal males in each of the three groups ( 5 males from R2, 4 males from PB1, 10 males from R1). Nine new males were added to the focal subject list as they migrated into the study groups. Three new adult males migrated into R1 and one new male migrated into PB1 from unhabituated groups. Three adult natal males from R2 migrated for the first time into R1, and two adult natal males from PB1 migrated for the first time into R1. One male migrated from $\mathrm{R} 2$ to R1, and thus has focal observations in both groups. Three additional adult males entered the study groups ( 2 in PB 1 and 1 in R1) but remained unhabituated during the time frame of the study. Five males left R1 before the end of the study. The total number of male subjects observed in each group was 5 males from R2, 5 males from PB1 and 19 males from R1. We focused on male-male relationships among nonnatal males, because assessments of social style typically focus on nonkin dyads to distinguish social style effects from kin selection effects (Thierry, 2007; Thierry et al., 2008), and nonnatal males are less likely to be related to other males than are natal males. Therefore, we excluded natal males from this study. Moreover, there were too few adult natal males to analyse separately. We recorded aggression, affiliation, displacements, submissive behaviour and silent bared-teeth displays in focal sessions that lasted $2 \mathrm{~h}$ when possible (mean length: $1.8 \mathrm{~h}$ ). Long focal follows were useful to obtain data on males whose rates of interactions are low and whose movement patterns and location were less predictable than those of females. Identities of the actor and recipient of behaviours were recorded as well as the sequence of events. Each day, focal males were selected from a predetermined random order, and sessions were evenly distributed across time of day for each male (5:45 am-9 am, 9 am-12 pm, 12 pm-3 pm, 3 pm-6 $\mathrm{pm})$. We performed point-time sampling every 2 min during focal sampling sessions during which we recorded the identities of other males within body contact, one body length $(0.5 \mathrm{~m}), 5$ body lengths $(2.5 \mathrm{~m})$ and $5 \mathrm{~m}$ of the 
focal. We also recorded the general activity of the group (whether the majority of the group was feeding, travelling or socialising) every $10 \mathrm{~min}$. Data were recorded directly into Toshiba Encore tablets with PTab spreadsheet program. We tested interobserver reliability between all pairs of observers, using Cohen's Kappa separately for behaviours (74-83\%), focal proximity to other males (77-100\%), group activity (range 70-100\%), and individual identification (100\%). Interobserver reliability was re-tested additional times throughout the study and some scores improved.

Data on female crested macaques were available for two groups R1 $(N=$ $21)$ and PB1 $(N=15)$, having been collected by Julie Duboscq, Jerome Micheletta and Dwi Yandhi Febriyanti from October 2008-May 2010 (Duboscq et al., 2013). Our team and Duboscq's team followed the same data collection protocol and used the same behavioural definitions. Both teams passed interobserver reliability tests with long-term Macaca Nigra Project field assistants for individual IDs and behavioural data collection.

\subsection{Behavioural definitions}

Aggressive interactions were defined as any aggressive behaviour that was followed by a response from the receiver (aggression, affiliation, submission). Aggressive behaviours were categorized as threats (aggressive vocalizations such as bark, grunt, rattle, and facial expressions such as half-open mouth, open mouth bared teeth), noncontact attacks (stamp, lunge, chase), contact attacks (hit, missed hit, grab, push) or bites (Thierry et al., 2000).

A displacement was defined as a nonaggressive approach by a male within $2.5 \mathrm{~m}$ while the approached male simultaneously moved away (Thierry et al., 2000).

Affiliative interactions included friendly behaviours such as grooming, embracing, grasping of fur, grasping of the genitals, male-male mounting, any nonaggressive body contact, presentation of hindquarters and friendly facial expressions such as lipsmacking (Thierry et al., 2000). A grooming bout consisted of any continuous episode of grooming with interruptions of no more than $10 \mathrm{~s}$. If an affiliative interaction consisted of only lipsmacking, it was categorized as noncontact affiliation. Interactions that included both contact and noncontact behaviours were scored as contact affiliation.

The silent bared-teeth display is a facial expression in which the upper or both lips are vertically retracted, in which with the corners of the mouth are drawn back, exposing the teeth and sometimes the gums (Thierry et al., 2000). 
We recorded nonagonistic approaches when a focal male approached another male within one bodylength (approximately $0.5 \mathrm{~m}$ ), and remained in proximity for $5 \mathrm{~s}$. We also recorded nonagonistic approaches within five bodylengths (approximately $2.5 \mathrm{~m}$ ). We classified outcomes of nonagonistic approaches as positive, negative or neutral. Positive outcomes were those in which the approaching male and/or the approached male engaged in affiliation within $10 \mathrm{~s}$. Negative outcomes were those in which the approached male aggressed or retreated from the approacher within $10 \mathrm{~s}$. Neutral outcomes were recorded if there was no observable action/reaction from either male within $10 \mathrm{~s}$.

\subsection{Data analysis}

We used only dyadic interactions between males during focal observations in the analysis. If more than one behaviour of the same category (i.e., affiliative, aggressive) were performed in succession between 2 individuals (within $10 \mathrm{~s}$ ), those behaviours were considered to be a single episode and were reported as a single interaction. If both agonistic and affiliative behaviours were exchanged within the same episode, the episode was scored as an agonistic interaction. Rates of behaviours (the total number of behavioural events performed by the focal subject divided by the total number of hours the focal subject was observed) and percentages of total behaviours (proportions of specific categories of behaviours out of all affiliative/aggressive behaviours) were calculated for each male. From these, group means and standard errors were derived.

\subsubsection{Aggression}

We calculated the percentages of total aggressive interactions that involved biting, contact attacks, noncontact attacks and threats. If multiple aggressive behaviours were exchanged between individuals within the same episode, the behaviour of highest intensity was used to classify the interaction (bite $>$ contact attack $>$ noncontact attack $>$ threat). Counteraggression was calculated as the percentage of aggressive interactions in which the recipient of aggression responded with aggression within 10 seconds.

\subsubsection{Affiliation}

The quality of affiliative interactions was assessed by calculating the percentage of total affiliative interactions involving body contact (e.g., mount, embrace, touch, grasp, grooming) for each male. Grooming rates were calculated for each male as the number of grooming bouts divided by the total 6 7 8 9 
observation hours for that male. A grooming bout consisted of immediately consecutive grooming episodes between two individuals that stopped and restarted within 10 seconds of each other.

\subsubsection{Conciliatory tendency}

The PC-MC method (de Waal \& Yoshihara, 1983) was used to test for the occurrence of post-conflict affiliation. A post-conflict observation period (PC) started immediately after an aggressive interaction ended between the focal male and an opponent male and lasted 5 min (per de Waal \& Yoshihara, 1983). All aggressive and affiliative behaviours exchanged between the focal male and the opponent were recorded. If aggression re-occurred within the PC, it was discarded and restarted once the new aggression ended. Matchedcontrol periods (MC) were extracted from focal data to compare the timing of the first affiliative contact in the PC and in the corresponding MC (Aureli, 1992). For each PC, a 5-min MC period was chosen based on the following criteria: the same opponent was within $5 \mathrm{~m}$ at the start of the MC, the opponents had not participated in aggression or affiliative interactions within 2 min of the start of the MC, and the general group activity was the same as in the PC. MC periods were within one month of the PC, when possible. If the first affiliative interaction between former opponents occurred earlier in the PC than MC, the pair was labelled 'attracted'. If the first affiliative interaction occurred earlier in the MC than $\mathrm{PC}$, or if it occurred in the MC but not in the PC, the pair was labelled 'dispersed'. If affiliation occurred at the same time in the PC and MC periods, or in neither PC nor MC periods, the pair was labelled 'neutral'. The corrected conciliatory tendency (CCT) was calculated in two ways: using contact affiliation only and using all affiliation (both contact and noncontact). CCTs were calculated for each individual with at least $2 \mathrm{PC}-\mathrm{MC}$ pairs as: (the number of attracted pairs number of dispersed pairs)/(total number of PC-MC pairs) (Veenema et al., 1994) for each individual, and then as a group mean.

\subsubsection{Dominance hierarchy}

Dominance hierarchies were constructed from the direction of displacements during stable periods (e.g., periods with no male migrations). We calculated the linearity index $h^{\prime}$, which corrects for unknown relationships (de Vries, 1995) and determined the rank order of individuals using the dominance matrix created by the I \& SI method (Matman 1.0). Hierarchical steepness, a measure of the extent to which an individual can exercise a negative influence 
on another individual (De Vries et al., 2006), was calculated using the slope of individual normalized David scores (Gammell et al., 2003). David scores were calculated using actor-receiver matrices based on dyadic aggressive interactions with a clear winner and loser (i.e., the receiver of aggression responded submissively by avoiding or fleeing). Steepness values range from 0 , indicating no differences in the relative abilities to win aggressive contests across adjacently-ranked individuals, to 1 , which indicates the maximum differences in such abilities to win aggressive contests. We report $D_{i j}$ dyadic dominance indices, which correct for chance observations by taking into account the frequency of interactions, and $P_{i j}$ indices which do not correct for interaction frequency (De Vries et al., 2006; Balasubramaniam et al., 2013).

\subsubsection{Silent-bared teeth display}

To determine the directionality of the silent bared-teeth display, we calculated the up-down index $(u /(u+d))$ for each individual (Castles et al., 1996), in which $u$ is the number of displays directed toward a higher ranking individual and $d$ is the number of displays directed to a lower ranking individual. An index of 0.5 indicates that there is no tendency for silent-bared teeth display to be directed up or down the hierarchy. An index higher than 0.5 indicates a tendency for the silent-bared teeth display to be directed up the hierarchy, while an index below 0.5 indicates a tendency for the display to be directed down the hierarchy (Castles et al., 1996). We performed binomial tests for each individual to determine whether the index differed significantly from 0.5 .

\subsection{Comparisons with other macaque males}

To compare male crested macaques with male macaques belonging to other species, we plotted crested male scores (mean across all individuals) along with published scores for other species. Due to the scarcity of comparable data, we were able to do this only for some social style measures. We included studies done both in the wild and in captivity. Since so few studies have examined male social style traits and made direct comparisons with females (e.g., Cooper \& Bernstein, 2008, Richter et al., 2009), social style grades have typically not been assigned separately to males. Thus, male macaque social style values are marked with symbols according to the social style grades assigned to the females of the same species (Figures 2-4). 


\subsection{Statistical analyses}

Analyses were performed in R 3.4.1 (R Core Team, 2017) using the R Stats Package and lme4 Package. Wilcoxon signed-ranks test were used to compare proportions of attracted vs. dispersed PC-MC pairs and to compare individuals' silent bared-teeth display up/down indices to neutral scores of 0.5 . We used linear regression models (LMs) to compare social style characteristics of crested macaque males across the three groups, and linear mixed models (LMMs) to compare the males with crested macaque females, controlling for group and rank. Our models satisfied general assumptions of linear regression models including non-multicollinearity (all VIF values $\leqslant$ 2), homoscedasticity (Non-Constant Error Variance test), no autocorrelation (Durbin-Watson test) and normality of residuals (Shapiro-Wilk test) (Field et al., 2012). To assess whether the social style characteristics and social interaction rates of males of different groups differed from each other, an LM was performed for each of the following dependent variables: rate of overall aggression, percentage of counteraggression, percentage of biting aggression, percentage of non-biting contact attacks, percentage of threat aggression, rate of overall affiliation, percentage of contact affiliation, rate of grooming, rate of nonagonistic approach within one and five bodylengths and percentage of positive/negative/neutral outcomes of approaches within one and five bodylengths. 'Group' was included as a fixed effect, and 'rank' was included as a control variable. Interactions between group and rank were removed from the model since they were insignificant for every dependent variable. To assess whether male social style characteristics differed significantly from those of females belonging to the same groups, we performed an LMM for each of the above listed dependent variables (except for rate of approach within 5 bodylengths and percentage of outcomes of approaches within 5 bodylengths, since these data were not available for the females). We entered sex as a fixed factor, group as a random factor and rank as a control. Where necessary to satisfy the assumptions of normality for both sets of analyses, the dependent variables were transformed using square root or cubed root transformations before analysis. In a few cases in which transformations were not sufficient to reach normality, we used nonparametric tests (MannWhitney $U$ or Kruskal-Wallis one-way ANOVA) to confirm the results of the LM and LMM tests. In all cases, the results of the LM and LMMs and nonparametric tests were consistent. Hence we report only the results of the LMs and LMMs. 


\section{Results}

For all rates and percentages of behaviours reported, $N=29$ males, unless otherwise noted.

\subsection{Aggression}

We recorded a total of 1483 aggressive interactions during the study. Overall, males engaged in aggression at an average rate of 0.55 interactions $/ \mathrm{h}$, with group means ranging between $0.23-0.70$ interactions/h (Table 1 ). The majority of aggressive interactions consisted of threats (1058 or $71.3 \%$ of all aggressive interactions). Biting was extremely rare and only occurred 2 times $(0.13 \%$ of total aggression). Attacks involving physical contact other than biting were also rare (40 interactions or $2.7 \%$ of total aggression), whereas noncontact attacks occurred 383 times (25.8\% of aggressive interactions). Counteraggression occurred 43 times (2.9\% of all aggressive conflicts).

\subsection{Affiliation and approach}

We recorded a total of 3483 affiliative interactions during the study. Males engaged in affiliative behaviours at a mean rate of 1.54 interactions $/ \mathrm{h}$, with group means ranging from $0.69-1.97$ interactions/h (Table 1). Grooming was extremely rare between males, occurring about once every $66 \mathrm{~h}$. Other types of affiliation involving body contact occurred 1279 times, making up $37.8 \%$ of all affiliative interactions.

Males approached other males within five bodylengths nonagonistically at a mean rate of $1.15 \pm 0.13$ (mean $\pm \mathrm{SE}$ ) times/h for a total of 6048 approaches. A large majority of outcomes of these approaches were neutral (no response) (4434; mean $=70.5 \%$; see Figure $1 \mathrm{~A}$ ). Nonagonistic approaches within one bodylength were relatively rare (total $=2168)$, occurring at mean rate of $0.45 \pm 0.05$ (mean $\pm \mathrm{SE}$ ) times/h, but when they did occur, the majority of outcomes were positive (1340; mean $=65.1 \%$; see Figure 1B). Most positive outcomes (71\%) involved brief exchanges (about 5-10 s) of body contact affiliation such as genital grasp, mount, embrace, mock bite or other friendly touch, after which the males did not remain in close proximity.

\subsection{Silent bared-teeth display}

We analysed 494 silent-bared teeth displays $\left(R_{1}=370\right.$, mean $=19 /$ male, range $=0-57 ; R_{2}=46$, mean $=9 /$ male, range $=0-15 ; \mathrm{PB} 1=78$, mean $=$ $15 /$ male, range $=0-32)$. Of them, $367(74 \%)$ were directed down, and 127 
A)

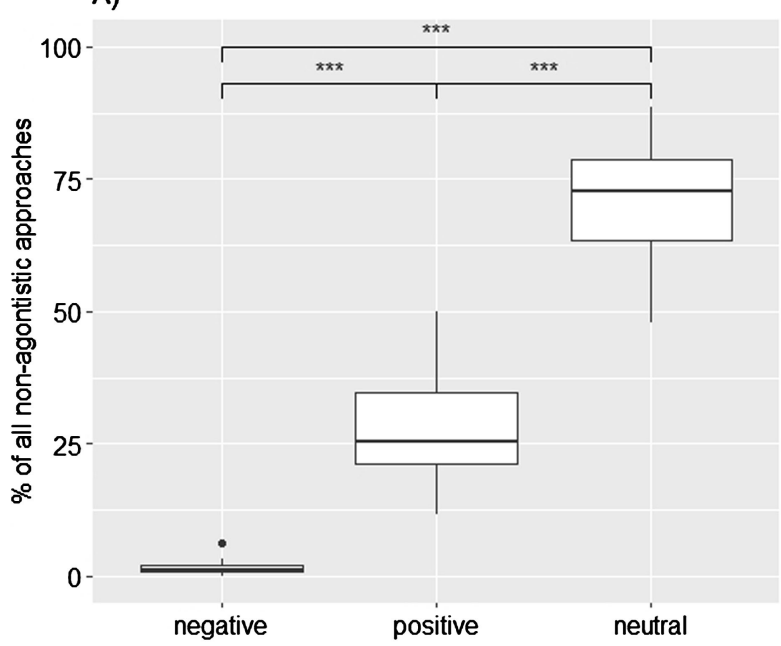

1

2

3

B)

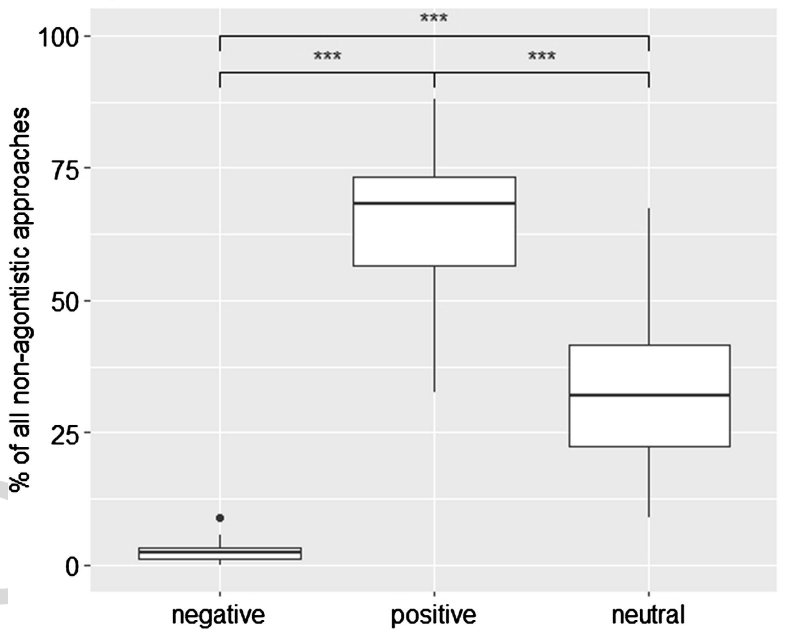

Figure 1. Proportions of types of outcomes following nonagonistic approaches between 30 males within five bodylengths (A) and one bodylength (B). (Medians, interquartiles (error bars), 1.5 interquartile ranges and outliers). ${ }^{* * *} p<0.001$, Mann-Whitney $U$ test.

(26\%) were directed up the hierarchy (mean \pm SE: $29 \pm 5 \%, N=28$ males). The overall up/down index was 0.26 , with group means ranging from $\quad 35$ 0.04-0.30 (Table 1). Individual index scores for males with at least 5 silent- 36 bared teeth displays were significantly different from a neutral score of $0.5 \quad 37$ 
(Wilcoxon signed-ranks: $V=16, N=24, p<0.001$ ), indicating a significant overall tendency for males to direct the display down the hierarchy. However, this tendency was neither displayed by all males nor wholly consistent among individual males, as would have been indicated by individual zero scores. Twenty-one individuals had up/down indices of less than 0.5, two had indices of more than 0.5 , and one had an index of exactly 0.5 . Separate binomial tests for each individual indicated that 13 of $24(54 \%)$ of males displayed up/down indices significantly lower than $0.5(p<0.05)$.

\subsection{Conciliatory tendency}

Out of a total of 540 PC-MC pairs $\left(\mathrm{R}_{1}: 428\right.$ pairs, $\mathrm{R}_{2}: 41$ pairs, $\mathrm{PB}_{1}: 71$ pairs), 92 were attracted, 42 were dispersed and 306 were neutral, yielding an overall CCT of $27.8 \%$. Group means were calculated from individuals CCT's $\left(\mathrm{R}_{1}: 28.8,(N=15)\right.$ males; $\mathrm{R}_{2}: 29.9 \%,(N=4)$, and PB1: $27.2 \%$ $(N=5)$. In $\mathrm{R}_{1}$, individuals had significantly higher proportions of attracted pairs than dispersed pairs (Wilcoxon signed-ranks test, $\mathrm{R}_{1}: V=91, p=$ 0.002), indicating that individuals engaged in affiliation at higher rates after aggression than at other times. All males in $\mathrm{R}_{2}$ and $\mathrm{PB}_{1}$, with one exception, also had higher proportions of attracted than dispersed pairs, but Wilcoxon signed-ranks tests did not reach significance $\left(\mathrm{R}_{2}: V=10, p=0.10 ; \mathrm{PB}_{1}\right.$ : $V=10, p=0.10)$.

\subsection{Dominance hierarchies}

R1 displayed a significantly linear dominance hierarchy (R1: $h^{\prime}=0.58$, $N=13, p=0.002$ ). Although $h^{\prime}$ was relatively high in the other two groups, it did not reach significance most likely due to small sample sizes $\left(\mathrm{R}_{2}: h^{\prime}=0.85, N=5, p=0.23 ; \mathrm{PB}_{1}: h^{\prime}=0.83, N=5, p=0.11\right)$; there were no inconsistencies in either group, and no two-way relationships in $\mathrm{PB}_{1}$. Hierarchies were moderately steep (Table 2). $p_{i j}$ steepness scores were slightly higher than $D_{i j}$ scores, but still in the moderately steep range. For both measures, $\mathrm{PB}_{1}$ displayed the lowest score, and $\mathrm{R}_{2}$ the highest.

\subsection{Comparisons with other macaque males}

The percentage of aggression followed by counteraggression among macaque males ( $N=10$ species, 12 groups) ranged from 0 to $75 \%$, with the majority of species under $27 \%$ (Figure 2). Compared to other macaque
10 
Table 2.

Steepness values using $D_{i j}$ and $p_{i j}$ scores.

\begin{tabular}{lccc} 
Group & $D_{i j}$ scores & $p_{i j}$ scores & $N_{\text {Interactions }}$ \\
\hline $\mathrm{R}_{1}$ & 0.33 & 0.42 & 360 \\
$\mathrm{~PB}_{1}$ & 0.31 & 0.40 & 57 \\
$\mathrm{R}_{2}$ & 0.54 & 0.68 & 48 \\
\hline
\end{tabular}

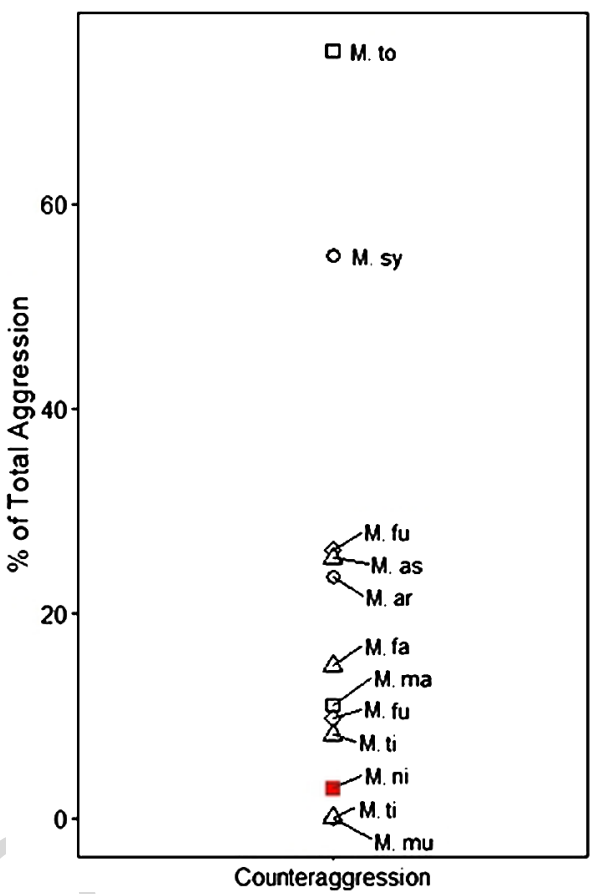

Figure 2. Comparison of percentages of aggression followed by counteraggression across macaque males.* Indicates captive group. (From top to bottom) M. tonkeana* (Thierry, 1985); M. sylvanus (Thierry \& Aureli, 2006); M. fuscata* (Petit et al., 1997); M. assamese (Cooper \& Bernstein, 2008); M. arctoides (Richter et al., 2009); M. fascicularis* (Thierry, 1985); M. maura (Riley et al., 2014); M. fuscata (Thierry, 1990)*; M. thibetana (Berman et al., 2004, period I); M. nigra (this study); M. thibetana (Berman et al., 2004, period II); $M$. mulatta* $^{*}$ (Thierry, 1985). Female social style grades based on Thierry (2007).

males, crested macaque males had the lowest levels of counteraggression 35 (2.9\%), after despotic rhesus $(0 \%)$ and Tibetan macaque males $(0 \%)$, consis- $\quad 36$ tent with a relatively despotic style. 

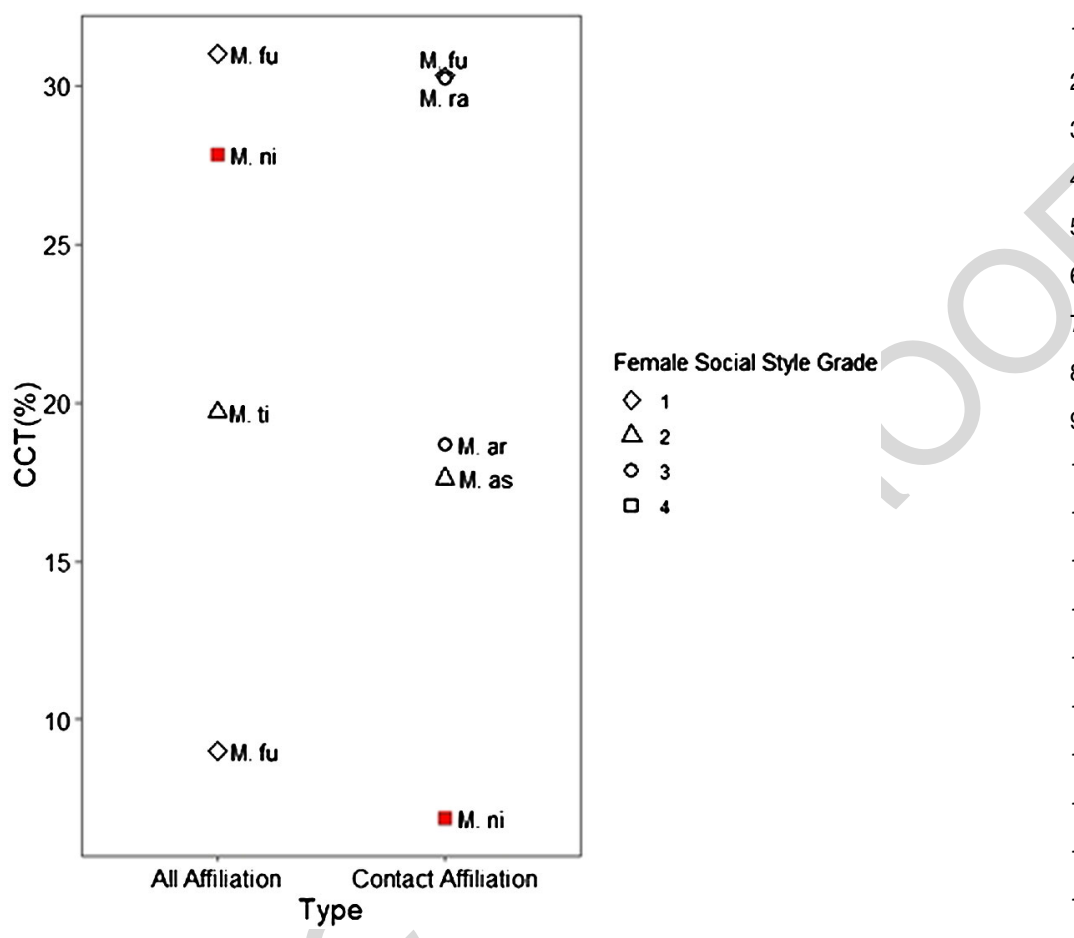

Figure 3. Comparison of conciliatory tendencies across macaque males. * Indicates captive group. All Affiliation: CCT's calculated by using all types of affiliation (From top to bottom): M. fuscata (Majolo et al., 2005); M. nigra (this study); M. thibetana (Berman et al., 2004); M. fuscata* (Schino et al., 1998); Contact Affiliation: CCT's calculated by using contact affiliation only (From top to bottom: M. fuscata* (Petit et al., 1997); M. radiata (Cooper et al., 2007); M. arctoides (De la O et al., 2013); M. assamensis (Cooper \& Bernstein, 2008); M. nigra (this study). Female social style grades based on Thierry (2007).

Male macaque conciliatory tendencies (CCT scores) ranged from 6.9$30.3 \%$ (Figure 3). Direct comparisons between macaque male concilia- 28 tory tendencies were difficult because studies included different age classes 29 (subadult and adults vs. adults only) and used different affiliation criteria (all 30 types of affiliation vs. contact affiliation only). In order to compare studies 31 that used both affiliation criteria, we calculated crested macaque scores both 32 ways and compared them separately with similar scores for other species. 33 Noncontact affiliation consisted almost entirely of lipsmacking for crested 34 males. Crested macaque male CCT score involving all types of affiliation 35 (27.8\%) was relatively high compared with other males $(N=3$ species, $4 \quad 36$ groups) (Figure 3). However, when only contact affiliation was considered, 
male crested macaque CCT score (6.9\%) was the lowest of all macaque 1 males ( $N=5$ species, 5 groups) (Figure 3 ), and comparable to extremely 2 despotic females, suggesting that crested macaque males engage in post- 3 conflict affiliation, but do so primarily by lipsmacking rather than via body contact.

Among macaque males, the percentage of total aggression involving biting was generally low (range $0-5.9 \%)(N=7$ species, 8 groups) (Figure 4$)$. Even so, crested macaque males had an extremely low level of biting compared to other males. Similarly, the percentage of contact attacks for crested

Figure 4. Comparison of aggression intensity across macaque males. * Indicates captive group. (A) Percentage of biting out of total aggression. From top to bottom: M. mulatta* (Thierry, 1985); M. fuscata* (Petit et al., 1997); M. assamensis (Cooper \& Bernstein, 2008); M. fuscata (Majolo et al., 2005); M. nigra (this study); M. maura (Riley et al., 2014); M. tonkeana* $^{*}$ (Thierry, 1985); M. fascicularis* (Thierry, 1985). (B) Percentage of contact aggression out of total aggression. M. fuscata* (Petit et al., 1997); M. tonkeana* (Thierry, 1985); M. mulatta* (Thierry, 1985); M. fuscata (Majolo et al., 2005); M. fascicularis* (Thierry, 
macaque males $(2.7 \%)$ was the lowest among other macaque male studies 1 (range 3.5-35.4\%) (Fig 4).

Taken together, these comparisons suggest that crested macaque male social style traits do not covary in a manner predicted by the social style hypothesis. Crested macaque male counteraggression is very low compared with other male macaques, i.e., on the more despotic end of the social style scale. However, aggression intensity and CCT (involving all types of affiliation) is high compared to other male macaques, i.e., on the more tolerant end of scale.

\subsection{Comparisons with crested macaque females}

Linear mixed models showed that sex is a significant predictor for all social 12 style measures (Table 3, Table A1 in the Appendix). R1 and PB1 males had 13 lower conciliatory tendencies and percentages of counteraggression, bites

Table 3.

Results of linear mixed models comparing behavioral measures of males and females from groups $\mathrm{R}_{1}$ and $\mathrm{PB}_{1}$.

\begin{tabular}{|c|c|c|c|c|}
\hline & Estimate & SE & $t$ & $p$ \\
\hline \multicolumn{5}{|l|}{ Social style measures } \\
\hline \multicolumn{5}{|l|}{ Outcome variable } \\
\hline CCT & -0.16 & 0.05 & -2.94 & $0.00^{* * * *}$ \\
\hline$\%$ Counteraggression & -3.59 & 0.42 & -8.51 & $0.00^{* * *}$ \\
\hline$\%$ Bite & -2.37 & 0.74 & -3.20 & $0.00^{* * * *}$ \\
\hline$\%$ Contact attack & -1.19 & 0.39 & -3.05 & $0.00^{* * *}$ \\
\hline$\%$ Threat & 12.02 & 4.71 & 2.56 & $0.01^{* *}$ \\
\hline \multicolumn{5}{|l|}{ Approaches within 1 bodylength } \\
\hline$\%$ Positive outcome & 34.33 & 2.33 & 14.76 & $0.00^{* * *}$ \\
\hline$\%$ Negative outcome & -0.90 & 0.23 & -3.82 & $0.00^{* * *}$ \\
\hline$\%$ Neutral outcome & -30.27 & 2.42 & -12.53 & $0.00^{* * *}$ \\
\hline \multicolumn{5}{|l|}{$\begin{array}{l}\text { Other measures of social interactions } \\
\text { Outcome variable }\end{array}$} \\
\hline Rate of overall aggression & 0.13 & 0.04 & 2.95 & $0.00^{* * *}$ \\
\hline Rate of overall affiliation & -0.37 & 0.07 & -5.60 & $0.00^{* * * *}$ \\
\hline Rate of grooming & -1.19 & 0.11 & -10.52 & $0.00^{* * *}$ \\
\hline$\%$ Body contact affiliation & -4.58 & 2.04 & -2.25 & $0.02^{*}$ \\
\hline Rate of approach (1 bodylength) & -4.84 & 0.30 & -16.23 & $0.00^{* * *}$ \\
\hline
\end{tabular}

Estimates are in reference to the fixed effect sex (male). Significant results are marked 36 with asterisks. 

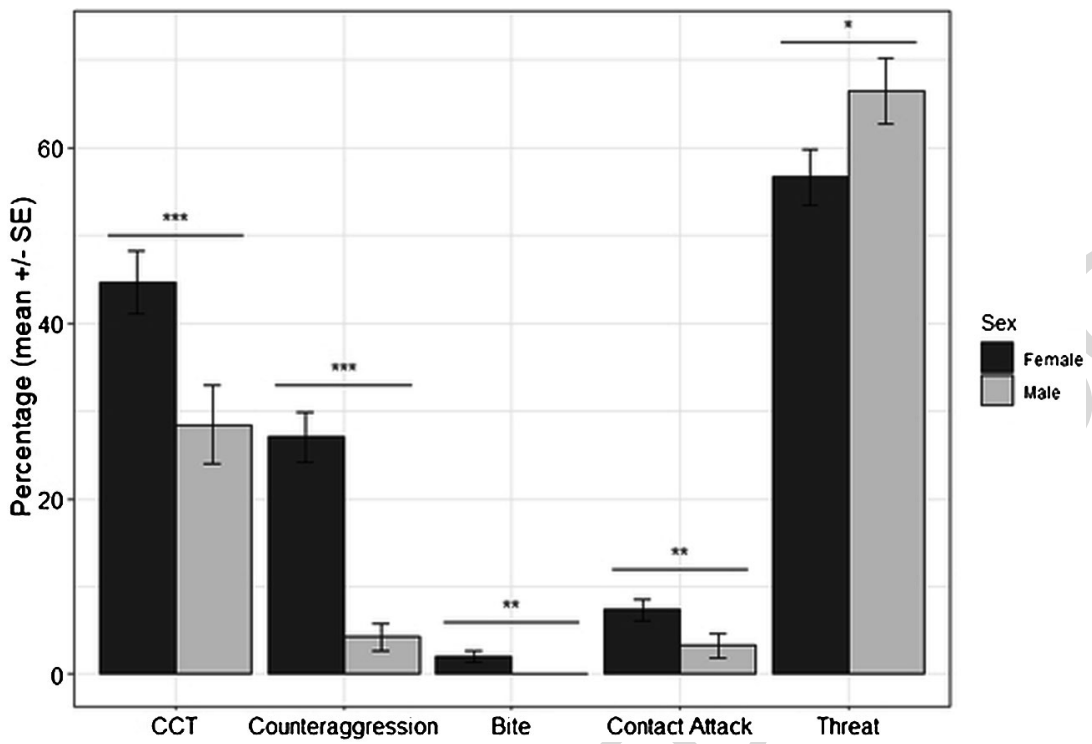

Figure 5. Comparison of crested macaque male and female social style measures: conciliatory tendencies, counteraggression, and percentages of biting, contact attacks and threats out of total aggression. Mann-Whitney $U$ tests significance values: $* p<0.05, * * p<0.01$, *** $p<0.001$.

and contact attacks than R1 and PB1 females, and higher percentages of threat aggression (Figure 5). They also had higher percentages of positive outcomes and lower percentages of both negative outcomes and neutral outcomes to nonagonistic approaches within one bodylength than females (Table 3). In addition, males had higher overall rates of aggression, lower rates of nonagonistic approaches within one bodylength than females (Table 3), and lower overall rates of affiliation than females. Finally, they engaged in less grooming and other affiliation involving body contact than females.

\subsection{Group comparisons}

Males in different social groups displayed similar social style traits: conciliatory tendencies, percent counteraggression and aggression intensity, including percent biting and contact attacks (Table 4, Figure 6ab, Table A2 in the Appendix). Following nonagonistic approaches within five bodylengths, they displayed similar percentages of positive, negative and neutral outcomes (Table 4). Similar percentages of positive, negative and neutral outcomes were also displayed following nonagonistic approaches within one bodylength 
BEH (brill2x v1.23) beh3597.tex 2020/04/21 8:43 [research-article] p. 25/41

M. Tyrrell et al. / Behaviour 0 (2020) 1-41

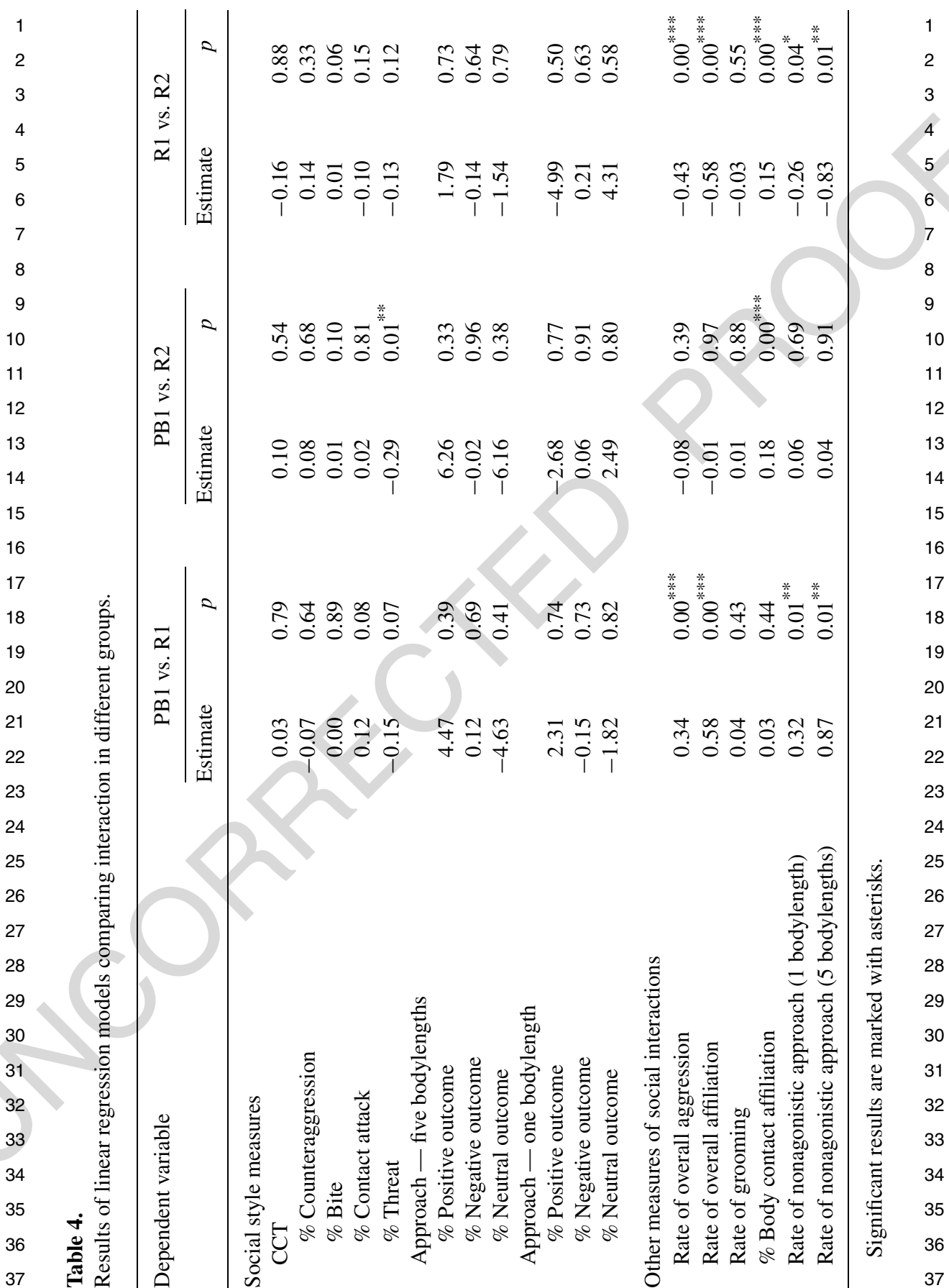




\section{A) Conciliatory Tendency}

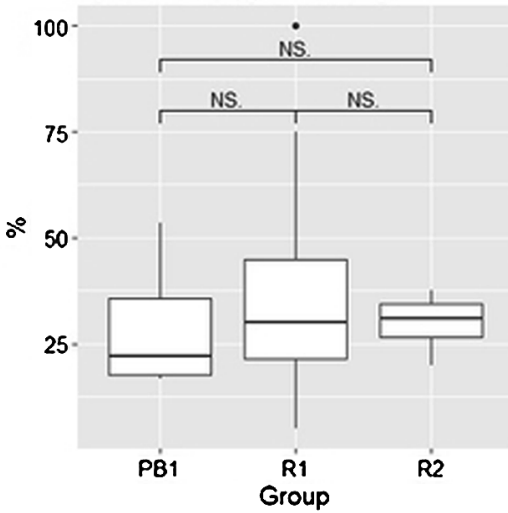

C) Overall Rate of Aggression

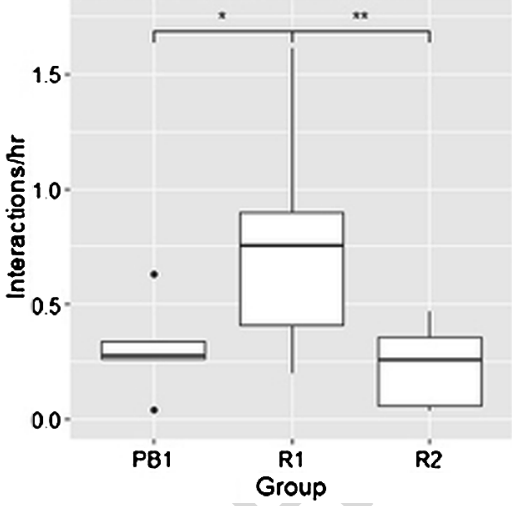

B) Counteraggression

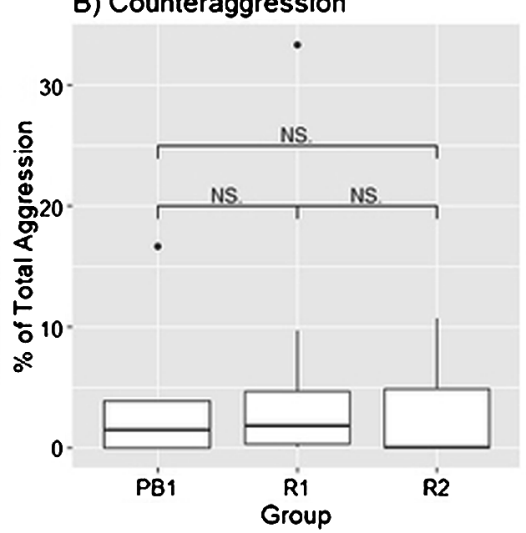

D) Overall Rate of Affiliation

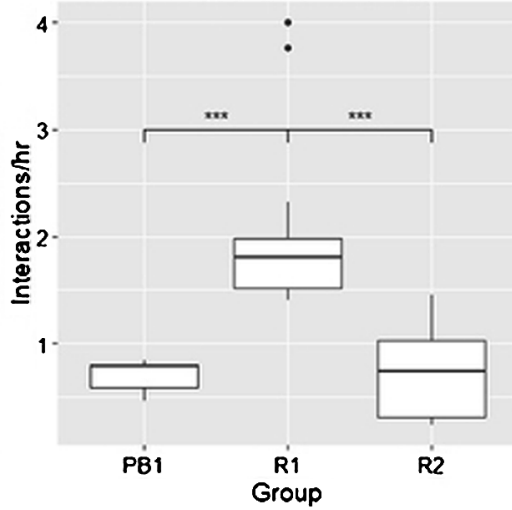

1

2

3

Figure 6. Group comparisons of two male social style measures (conciliatory tendency (A) and counteraggression (B)), overall rate of aggression (C) and affiliation (D). (Median, interquartiles (error bars), 1.5 interquartile ranges and outliers). * $p<0.05 ; * * p<0.01$; *** $p<0.001$, Mann-Whitney $U$-test.

(Table 4). The only exception was for percent threats, a form of mild aggression, which was significantly lower in $\mathrm{R}_{2}$ than $\mathrm{PB}_{1}$. In contrast, males displayed more marked group differences in rates of (1) overall aggression, (2) nonagonistic approaches within one bodylength and five bodylengths, and (3) affiliative behaviours: overall affiliative behaviour, contact affiliation, but not grooming (Table 4, Figure 6cd, Appendix Table II). $\mathrm{R}_{1}$ had significantly higher rates of overall affiliation, aggression, and nonagonistic approaches than $\mathrm{PB}_{1}$ and $\mathrm{R}_{2}$. $\mathrm{R}_{2}$ had a higher percentage of contact affiliation than $\mathrm{R}_{1}$ and $\mathrm{PB}_{1}$. 


\section{Discussion}

Although it is well established that female crested macaques display extremely tolerant social styles, male crested macaques have been inconsistently characterized as both tolerant and extremely hostile. We examined core social style traits and other measures of social interaction in adult males in three groups of wild crested macaque males in order to characterize their relationships with one another and to ask whether they are consistent with a particular social style (despotic, tolerant or intermediate). We found that males displayed a mixture of tolerant and despotic social style indicators, rather than displaying all indicators consistently on one end of the social style scale, or consistently intermediate. These findings are not consistent with the notion of covariation among social style traits. Relative to other males, crested macaque males had extremely low percentages of biting and other types of contact aggression, typical of tolerant species, but they also had extremely low levels of counteraggression, typical of despotic species. In general, male counteraggression did not appear to correspond to the social style grade assigned to females; although the two highest scores were for species with tolerant females, male scores for species with females in grades 1, 2 and 4 had broadly overlapping ranges. Although we did not limit our measure of counteraggression to nonfood or nonmating contexts, as some captive studies have done, instances of counteraggression were very infrequent in all contexts. When lipsmacking was counted as an affiliative gesture, conciliatory tendencies were high compared to other males, typical of tolerant species, but when they were not counted as affiliative, conciliatory tendencies were extremely low, typical of despotic species. Nevertheless, either way, crested males displayed a mix of tolerant and despotic traits. Additionally, males had moderate levels of hierarchical steepness, and they tended to direct the silent-bared teeth display down the dominance hierarchy. As expected for sexes that are subject to differing selective pressures, males also differed significantly in social style traits and other types of social interactions when compared to females from the same social groups. Compared to females, males had lower conciliatory tendencies (counting lipsmacking for both sexes) and lower percentages of counteraggression, suggesting less tolerance, but also lower percentages of biting and other contact aggression, suggesting more tolerance. Moreover, males showed much lower overall rates of nonagonistic approaches and affiliation than females and almost no grooming. Their low levels of affiliative interaction and their avoidance of 
reconciliation involving contact, suggest that their relationships do not reflect the typically affiliative and relaxed nature of female crested macaque relationships or those of other tolerant species. We hypothesize that the apparent tolerance among male crested macaques may be better described as avoidance due perhaps to tension over high levels of risky reproductive competition. We develop this hypothesis below as we discuss our findings in more detail.

Past studies have dealt with evidence of mixed tolerant and despotic traits, including extreme scores in both directions, in at least two ways. Early studies (Castles et al., 1996; Cooper \& Bernstein, 2002; Berman et al., 2004; Thierry, 2007) placed them in intermediate positions on the social style scale, even though the covariation hypothesis predicts consistently intermediate traits. However more recent studies and reviews (Balasubramaniam et al., 2020; Berman et al., 2007; Kaburu \& Newton-Fisher, 2015) have proposed more nuanced interpretations, for male social styles in particular. These studies suggest that signs of male-male social tolerance can emerge from despotic dominance styles and may represent an adaptive outgrowth of within-group competition that allows males to avoid injury and/or enhance their competitive abilities by displaying tolerance to other males. For example, male chimpanzees display characteristics typical of a despotic social style (steep dominance hierarchies in many communities and high reproductive skew), yet they also show signs of a more relaxed dominance style; dominants show tolerance to subordinates and provide agonistic support, and grooming relationships are highly reciprocal (Kaburu \& NewtonFisher, 2015). Kaburu \& Newton-Fisher (2015) coined the term 'egalitarian despots' to describe male chimpanzees with this seemingly contradictory mix of traits. Displays of tolerance by male chimpanzees are hypothesized to be dependent on sociodemographic factors (i.e., the number of males aged 20-30 years in the group), rather than an inherent characteristic of the species (Kaburu \& Newton-Fisher, 2015). In groups with a high number of equally matched male competitors, despotism was constrained and hierarchical steepness tended to be lower (Kaburu \& Newton-Fisher, 2015). Similarly, Tibetan macaque males have a mix of despotic and tolerant traits. Low percentages of counteraggression, the use of the silent-bared teeth display as a submissive signal and a high degree of competition over fertile females point to highly asymmetric dominance relationships ( $\mathrm{Li}, 1999$; Berman et al., 2004), but the males also show affiliative behaviours that are associated 
with tolerant species, including moderate conciliatory tendencies, ritualized greetings and triadic interactions involving infants that facilitate friendly interactions and social bonding between males (Ogawa, 1995). Furthermore, high ranking males may increase tolerance towards lower ranking males as a way to discourage revolutionary alliances (Berman et al., 2007). Taking after Kaburu \& Newton-Fisher's description of male chimpanzee relationships, Balasubramaniam et al. (2020) refer to Tibetan macaque males as 'tolerant despots' to describe the emergence of tolerance despite evidence of despotism.

Finally, Barbary macaque males exhibit social style traits on both ends of the continuum. Barbary macaque males intensely compete over females but have apparently tolerant relationships in that they rarely engage in overt aggression outside of the mating season, lack formalized submissive signals and engage in affiliative interactions (Paul et al., 1996; Preuschoft et al., 1998; Berghänel et al., 2011). In competitive situations, they tend to ignore and avoid each other rather than behave aggressively (Preuschoft et al., 1998). However, when physical aggression does break out among males, it can result in severe injuries. Thus, the apparent tolerance between males appears to be a result of a stalemate between dangerous males. Avoidance may be viewed as an important de-escalation tactic to deal with intense withingroup competition. Stumptail macaque males have been observed to display a general avoidance of all types of interactions, in that they have very low rates of affiliation, including behaviours such as grooming and other friendly body contacts, as well as low rates of aggressive behaviours compared to female conspecifics (Richter et al., 2009). Male-male avoidance in stumptail macaques, like Barbary macaques, is hypothesized to prevent conflicts and serious injuries. This idea of avoidance as a strategy may also have relevance for crested macaque male relationships. In addition to our findings of a mix of extreme and intermediate social style scores, they face high within-group competition over fertile females in which the highest-ranking males sire the majority of offspring (Engelhardt et al., 2017). Although biting and contact aggression was rarely observed during focal sessions, serious injuries have been observed resulting from fights between males, especially when males migrate into new groups (Marty et al., 2016, 2017; personal observation). As such, we suggest that tolerance in crested macaque males may not be based on friendliness and relaxed relationships, but may be better described as another pattern of avoidance, similar to those seen in male stumptail macaques and Barbary macaques. 
The argument that the apparent tolerance displayed by crested macaque males does not emerge from social tolerance per se or affiliative tendencies, but rather from tendencies to avoid social contact, is highlighted when comparing them to females, whose relationships have been consistently described as friendly and relaxed. For example, although males had significantly higher rates of aggression than females, they had significantly lower percentages of biting and contact aggression, but higher proportions of threat aggression, involving no contact. This suggests, that although males engaged in a substantial amount of hostile behaviour, they avoided actual contact during aggressive interactions. In addition, males had significantly lower conciliatory tendencies and counteraggression than females, suggesting that they were less able to manage aggression through post conflict affiliation and less willing to challenge aggressors. Moreover, when they engaged in post conflict affiliation, they primarily did so using lipsmacking and rarely with affiliative contact. Rates of nonagonistic approach and affiliative interaction also suggest avoidance in males. In contrast to females, rates of close approach and affiliation among males were very low. Although nonagonistic approaches led on most occasions to an affiliative act involving brief contact, in general males used predominantly noncontact modes of affiliation when they did engage affiliatively. As with post conflict affiliation, lipsmacking was the most common affiliative behaviour used by males in these contexts, and unlike females, they typically did not remain within one bodylength for more than 5-10 s. Also unlike females who groomed at high rates, males engaged in virtually no grooming of one another. Although rates of grooming and proximity may be influenced by a variety of factors, making it difficult to compare directly, crested male rates of grooming and proximity contrast even with those of extremely despotic male macaques, suggesting a distinction between despotism per se and avoidance. For example, Horiuchi (2007) reported individual mean grooming rates/h in despotic Japanese macaque males of 0.07 at Shimokita Peninsula and 0.8 at Yakushima vs. 0.015 in our subjects. Similarly, Drickamer (1976) reported per dyad grooming rates/h among male rhesus on Cayo Santiago of 0.016 vs. $<0.001$ in our subjects (see also Kaufman, 1967). Finally, our data suggest that crested male dyads appear to spend a smaller proportion of time within $5 \mathrm{~m}$ of each other than Japanese macaque males $(0.017$ vs. 0.022$)$ (dyadic proximity ratio estimated from graph; Kawazoe, 2016). Given their mix of despotic and 
tolerant characteristics, labels of a distinctly 'tolerant' or 'despotic' or 'intermediate' social style do not seem an appropriate fit for crested males. Due to signs of avoidance of contact, and in light of their intense competition over females, a more fitting description of their social style may be 'avoidant'. The use of the term 'avoidant' distinguishes crested macaque males from males described as 'egalitarian or tolerant despots' (i.e., chimpanzees and Tibetan macaques) whose tolerance appears to be more calmly bestowed by dominants on subordinates. Whether or not male crested macaques also use tolerance strategically or selectively like chimpanzees and Tibetan macaque males is as yet unknown.

In addition to several core social style traits, we also examined the use of the silent bared-teeth display in crested macaque males and found that it differs from macaque species on both extreme ends of the social style scale. Thus its function appears to differ from either despotic or tolerant macaque species. The strong tendency for crested macaque males to direct the silent-bared teeth display down the hierarchy raises the hypothesis that it may communicate dominant status in adult males. However, if so, it is not a formal signal of dominance, because it is not consistently directed by dominants to subordinates. On the other hand, it may be that it functions as a friendly expression as it does in females, but that unlike females, dominant partners are more likely to initiate the display with subordinate partners than vice-versa, perhaps to communicate a benign intent towards subordinates. At this point, whether it conveys a message related to dominance per se or not is unclear. A more detailed examination of the context and function of the display in crested macaque males is forthcoming.

A recent hypothetical evolutionary explanation for the occurrence of species with mixed despotic and tolerant traits is based on phylogenetic and comparative analyses of social style traits as well as evidence that some traits are influenced by more recent socioecological conditions (Balasubramaniam et al., in 2020). It suggests that patterns of covariation (and the lack thereof) among macaque species is consistent with the idea that covariation among social style traits was present in the distant evolutionary past of the genus, but that it has been subsequently modified by semi-independent responses to variation in current conditions. Specifically, it cites evidence for co-variation between some social style traits and social style grade across some macaques in different phylogenetic lineages, but not across species within the same 
lineage. In addition, it points out that some social style traits also vary between groups within species (e.g., Zhang \& Watanabe, 2014) and that some traits are more strongly influenced by varying external circumstances such as group size (Balasubramaniam et al., 2018) and human disturbance (Berman et al., 2004) than by phylogeny. Assuming that this hypothesis is correct, we speculate below about particular current circumstances that could have an influence on crested macaque male social style traits. Like Tibetan macaques, our crested macaque study groups were subject to disturbance by tourism (Berman et al., 2004, 2007) as well as by crop-guarding, factors that may have either led to more despotism due to high levels of stress, or to more tolerance in response to an external threat. While human disturbance may have had a general effect on the crested macaque population, it did not appear to affect groups differentially, as might be expected. One of the study groups, PB1, experienced minimal levels of tourism and crop guarding compared with the other two groups. Yet, there were no differences in social style traits among the three groups, results that are consistent with most other studies of intraspecific group differences in social style traits (Thierry et al., 2008; but see Horiuchi, 2007; Majolo et al., 2009; Zhang \& Watanabe, 2014). Larger group size is hypothesized to lead to despotic styles due to increased contest competition over resources (Koenig et al., 2013; Sterck et al., 1997; van Schaik, 1989) and/or increased temporal constraints (Berman \& Thierry, 2010; Dunbar, 1992). The groups varied in size from 33 adults in PB1 and R2 to about 45 adults in R1, without differing in social style traits, although group size may have played a role in the differences in rates of social affiliation, aggression and nonagonistic approaches that we found; R1 males showed higher rates of affiliation, aggression and nonagonistic approaches than the other two groups.

High levels of intergroup competition have also been hypothesized to lead to tolerant behaviour among species also living under conditions of high within-group competition (Sterck et al., 1997; Horuichi, 2007; Majolo et al., 2009). Given that crested macaque males experience high reproductive skew within groups (Engelhardt et al., 2017) as well as frequent intergroup encounters and attempts at male immigration (Marty et al., 2016, 2017; Martínez Íñigo, 2018), this explanation may also apply generally to the population. However, again it does not appear to apply to group differences in social style traits which did not vary between social groups, in spite of the fact that R1 experienced higher rates of intergroup encounters and 
male migration than the other two groups. Finally, near equal sex ratios have been suggested to promote cooperation, affiliation and tolerance in macaque males, for example, in Barbary, Assamese, Tibetan, and bonnet macaques (Silk, 1994; Preuschoft \& Paul, 2000; Cooper \& Bernstein, 2002; Adisehan et al., 2011; see also Horiuchi, 2007). However, this explanation is not likely to apply to this population given that male to female sex ratios were low among all the groups $\left(\mathrm{R}_{1}=0.30-0.39 ; \mathrm{R}_{2}=0.22 ; \mathrm{PB}_{1}=0.27\right)$. Clearly further research is needed to examine the influence of each of these factors and other factors not considered here, and to evaluate whether they can exert population level influences on social style traits, without leading necessarily to intergroup variation (see Balasubramaniam et al., 2014).

In summary, this study suggests that the avoidant relationships of male crested macaques do not fit neatly onto the four-grade social style scale. Unlike their female counterparts who display consistently tolerant traits and relaxed and friendly affiliative relationships, male-male relationships are marked by a combination of despotic traits, tolerant traits and low sociability. Although males do not engage in high rates of contact aggression with each other, they have tense, competitive relationships marked by avoidance of all types of interaction. Such combinations of social style traits, along with social avoidance may represent more nuanced relationship qualities that emerge when competing males attempt to use tolerance to avoid the costs of competition or other external circumstances.

In addition to illustrating the avoidant tendencies of males, our results add to the growing realization that males should not be assumed to have similar social styles as the females of the same species; males of several species do not exhibit social style measures predicted by the grade assigned to females. Instead, social style traits should be examined in males and females separately. Additional measures other than traditional social style indicators may be necessary to get more accurate and general depictions of relationships between males (e.g., affiliative behaviour, ritualized greetings, coalitionary support). Finally, more comparative studies investigating male social relationships are needed to fill in the gaps of our knowledge of the evolution of male social styles.

\section{Acknowledgements}

We thank the Indonesian State Ministry of Research and Technology (RIS- 
(PHKA) and the Department for the Conservation of Natural Resources (BKSDA) for permission to conduct research in Tangkoko Nature Reserve. We are grateful to Enggar Oktaviyanti, Diah Fitri Ekarini and Santi Julianti for help with data collection. We thank Stephan Lentley for administrative support, Dwi Yandhi Febriyanti and the Macaca Nigra Project staff for support in the field. We are grateful to two anonymous reviewers for their comments and suggestions that greatly improved the manuscript, as well as Bernard Thierry and Krishna Balasubramaniam for helpful comments and suggestions on an earlier version of the manuscript. This project was funded by the Leakey Foundation, National Geographic Waitt Program (grant no. 4241-6), American Society of Primatologists, International Society of Primatologists, Animal Behavior Society, Nacey Maggioncalda Research Foundation (grant No. 415483), Mark Diamond Research Fund (grant No. SU-15-14) and the University at Buffalo College of Arts and Sciences Dissertation Writing Grant.

\section{References}

Adiseshan, A., Adiseshan, T. \& Isbell, L.A. (2011). Affiliative relationships and reciprocity among adult male Bonnet macaques (Macaca radiata) at Arunachala Hill, India. - Am. J. Primatol. 73: 1107-1113.

Altman, J. (1974). Observational study of behaviour sampling methods. - Behaviour 49: 227-267.

Aureli, F. (1992). Post-conflict behaviour among wild long-tailed macaques (Macaca fascicularis). - Behav. Ecol. Sociobiol. 31: 329-337.

Balasubramaniam, K.N., Beisner, B.A., Berman, C.M., De Marco, A., Duboscq, J., Koirala, S., Majolo, B., MacIntosh, A.J., McFarland, R., Molesti, S., Ogawa, H., Petit, O., Schino, G., Sosa, S., Sueur, C., Thierry, B., de Waal, F.B.M. \& McCowan, B. (2018). The influence of phylogeny, social style, and sociodemographic factors on macaque social network structure. - Am. J. Primatol. 80: 1-15.

Balasubramaniam, K.N., Berman, C.M., De Marco, A., Dittmar, K., Majolo, B., Ogawa, H., Thierry, B. \& De Vries, H. (2013). Consistency of dominance rank order: a comparison of David's scores with I\&SI and Bayesian methods in macaques. - Am. J. Primatol. 75: 959-971.

Balasubramaniam, K.N., Berman, C.M., Ogawa, H. \& Li, J. (2011). Using biological markets principles to examine patterns of grooming exchange in Macaca thibetana. - Am. J. Primatol. 73: 1269-1279.

Balasubramaniam, K.N., Dittmar, K., Berman, C.M., Butovskaya, M., Cooper, M.A., Majolo, B., Ogawa, H., Schino, G., Thierry, B. \& de Waal, F.B.M. (2012). Hierarchical steepness, counter-aggression, and macaque social style scale. — Am. J. Primatol. 74: 915-925. 
Balasubramaniam, K.N., Dunayer, E.S., Gilhooly, L.J., Rosenfield, K.A. \& Berman, C.M. (2014). Group size, contest competition, and social structure in Cayo Santiago rhesus macaques. - Behaviour. 151: 1759-1798.

Balasubramaniam, K.N., Ogawa, H., Li, JH., Ionica, C. \& Berman, C.M. (2020). Tibetan macaque social style: covariant and quasi-independent evolution. - In: The behavioral ecology of the Tibetan macaque (Li, J.H., Sun, L. \& Kappeler, P., eds). Fascinating life sciences. Springer, Cham, p. 141-169.

Berghänel, A., Ostner, J., Schröder, U. \& Schülke, O. (2011). Social bonds predict future cooperation in male Barbary macaques, Macaca sylvanus. — Anim. Behav. 81: 11091116.

Berman, C.M., Ionica, C. \& Li, J. (2007). Supportive and tolerant relationships among male Tibetan macaques at Huangshan, China. — Behaviour 144: 631-661.

Berman, C.M., Ionica, C.S. \& Li, J. (2004). Dominance style among Macaca thibetana on Mt. Huangshan, China. — Int. J. Primatol. 25: 1283-1312.

Berman, C.M. \& Thierry, B. (2010). Variation in kin bias: species differences and time constraints in macaques. - Behaviour 147: 1863-1887.

Butovskaya, M. (1993). Kinship and different dominance styles in groups of three species of the genus macaca (M. arctoides, M. mulatta, M. fascicularis). — Folia Primatol. 60: 210-224.

Castles, D.L., Aureli, F. \& De Waal, F.B.M. (1996). Variation in conciliatory tendency and relationship quality across groups of pigtail macaques. — Anim. Behav. 52: 389-403.

Clutton-Brock, T. \& Janson, C. (2012). Primate socioecology at the crossroads: past, present, and future. - Evol. Anthropol. 21: 136-150.

Cooper, M.A., Aureli, F. \& Singh, M. (2007). Sex differences in reconciliation and postconflict anxiety in Bonnet macaques. — Ethology 113: 26-38.

Cooper, M.A. \& Bernstein, I.S. (2002). Counter aggression and reconciliation in Assamese macaques (Macaca assamensis). - Am. J. Primatol. 56: 215-230.

Cooper, M.A. \& Bernstein, I.S. (2008). Evaluating dominance styles in Assamese and rhesus macaques. - Int. J. Primatol. 29: 225-243.

De la O, C., Mevis, L., Richter, C., Malaivijitnond, S., Ostner, J. \& Schulke, O. (2013). Reconciliation in male stump-tailed macaques (Macaca arctoides): intolerant males care for their social relationships. - Ethology 119: 39-51.

de Vries, H. (1995). An improved test of linearity in dominance hierarchies containing unknown or tied relationships. - Anim. Behav. 50: 1375-1389.

de Vries, H., Stevens, J.M.G. \& Vervaecke, H. (2006). Measuring and testing the steepness of dominance hierarchies. - Anim. Behav. 71: 585-592.

de Waal, F.B.M. \& Luttrell, L.M. (1985). The formal hierarchy of rhesus macaques: an investigation of the bared-teeth display. - Am. J. Primatol. 9: 73-85.

de Waal, F.B.M. \& Luttrell, L.M. (1989). Toward a comparative socioecology of the genus Macaca: different dominance styles in rhesus and stumptail monkeys. — Am. J. Primatol. 19: 83-109.

de Waal, F.B.M. \& Ren, R.M. (1988). Comparison of the reconciliation behavior of stumptail and rhesus macaques. — Ethology 78: 129-142. 
de Waal, F.B.M. \& Yoshihara, D. (1983). Reconciliation and redirected affection in rhesus monkeys. - Behaviour 85: 224-241.

Demaria, C. \& Thierry, B. (2001). A comparative study of reconciliation in rhesus and Tonkean macaques. - Behaviour. 138: 397-410.

Di Fiore, A. \& Rendall, D. (1994). Evolution of social organization: a reappraisal for primates by using phylogenetic methods. — Proc. Natl. Acad. Sci. USA 91: 9941-9945.

Dixson, A.F. (1977). Observations on the displays, menstrual cycles and sexual behaviour of the "Black ape" of Celebes (Macaca nigra). — J. Zool. 182: 63-84.

Drickamer, L. (1976). Quantitative observations of grooming behavior in free-ranging Macaca mulatta. - Primates 17: 323-335.

Duboscq, J., Micheletta, J., Agil, M., Hodges, K., Thierry, B. \& Engelhardt, A. (2013). Social tolerance in wild female crested macaques (Macaca nigra) in Tangkoko-Batuangus Nature Reserve, Sulawesi, Indonesia. - Am. J. Primatol. 75: 361-375.

Dunbar, R.I.M. (1992). Time: a hidden constraint on the behavioural ecology of baboons. Behav. Ecol. Sociobiol. 31: 35-49.

Emlen, S.T. \& Oring, L.W. (1977). Ecology, sexual selection, and the evolution of mating systems. - Science 197: 215-233.

Engelhardt, A., Muniz, L., Perwitasari-Farajallah, D. \& Widdig, A. (2017). Highly polymorphic microsatellite markers for the assessment of male reproductive skew and genetic variation in critically endangered crested macaques (Macaca nigra). — Int. J. Primatol. 38: 672-691.

Field, A., Miles, J. \& Field, Z. (2012). Discovering statistics using R. — Sage, London.

Fooden, J. (1969). Taxonomy and evolution of the monkeys of Celebes (Primates: Cercopithecidae). - Karger, Basel.

Gammell, M.P., de Vries, H., Jennings, D.J., Carlin, C.M. \& Hayden, T.J. (2003). David's score: a more appropriate dominance ranking method than Clutton-Brock et al.'s index. Anim. Behav. 66: 601-605.

Harcourt, A.H., Harvey, P.H., Larson, S.G. \& Short, R.V. (1981). Testis weight, body weight and breeding system in primates. - Nature 293: 55-57.

Harvey, P.H., Purvis, A. \& Liles, L. (1995). Sperm competition: mating system, not breeding system, affects testes size of primates. - Funct. Ecol. 9: 468-476.

Hill, D.A. (1994). Affiliative behaviour between adult males of the genus macaca. - Behaviour 130: 293-308.

Horiuchi, S. (2007). Social relationships of male Japanese macaques (Macaca fuscata) in different habitats: a comparison between Yakushima island and Shimokita peninsula populations. - Anthropol. Sci. 115: 63-65.

Isbell, L.A. (2017). Socioecological model. — In: The international encyclopedia of primatology, 1 (Bezanson, M., MacKinnon, K.C., Riley, E., Campbell, C.J., Nekaris, K.A.I., Estrada, A., Di Fiore, A.F., Ross, S., Jones-Engel, L.E., Thierry, B., Sussman, R.W., Sanz, C., Loudon, J., Elton, S. \& Fuentes, A., eds). Wiley Online Library, London.

Janson, C. \& Van Schaik, C.P. (1988). Recognizing the many faces of primate food competition: methods. - Behaviour 105: 165-186. 
Kaburu, S.S.K. \& Newton-Fisher, N.E. (2015). Egalitarian despots: hierarchy steepness, reciprocity and the grooming-trade model in wild chimpanzees, Pan troglodytes. - Anim. Behav. 99: 61-71.

Kamilar, J. \& Cooper, N. (2015). Phylogenetic signal in primate behaviour, ecology and life history. — Philos. Trans. Roy. Soc. B: Biol. Sci. 368: 20120341.

Kappeler, P.M. \& Van Schaik, C.P. (2002). Evolution of primate social systems. — Int. J. Primatol. 23: 707-740.

Kaufman, J.H. (1967). Social relations of adult males in a free-ranging band of rhesus monkeys. - In: Social communication among primates (Altmann, S., ed.). University of Chicago Press, Chicago, IL, p. 73-98.

Kawazoe, T. (2016). Association patterns and affiliative relationships outside a troop in wild male Japanese macaques, Macaca fuscata, during the non-mating season. - Behaviour 153: 69-89.

Koenig, A., Scarry, C.J., Wheeler, B.C. \& Borries, C. (2013). Variation in grouping patterns, mating systems and social structure: what socio-ecological models attempt to explain. Philos. Trans. Roy. Soc. B: Biol. Sci. 368: 20120348.

Li, J. (1999). The Tibetan macaque society: a field study. - Anhui University Press, Hefei.

Majolo, B., Ventura, R. \& Koyama, N. (2005). Postconflict behavior among male Japanese macaques. - Int. J. Primatol. 26: 321-336.

Majolo, B., Ventura, R., Koyama, N., Hardie, S.M., Jones, B.M., Knapp, L.A. \& Schino, G. (2009). Analysing the effects of group size and food competition on Japanese macaque social relationships. - Behaviour 146: 113-137.

Martínez Íñigo, L. (2018). Intergroup interactions in crested macaques (Macaca nigra): factors affecting intergroup encounter outcome and intensity. — Doctoral dissertation, University of Lincoln, Lincoln, NE.

Marty, P.R., Hodges, K., Agil, M. \& Engelhardt, A. (2016). Determinants of immigration strategies in male crested macaques (Macaca nigra). - Sci. Rep. 6: 32028.

Marty, P.R., Hodges, K., Agil, M. \& Engelhardt, A. (2017). Alpha male replacements and delayed dispersal in crested macaques (Macaca nigra). — Am. J. Primatol. 79: e22448.

Matsumura, S. (1999). Evolution of "egalitarian" and "despotic" social systems among macaques. - Primates 40: 23-31.

Menard, N. (2004). Do ecological factors explain variation in social organization?. - In: Macaque societies: a model for the theory of social organization (Thierry, B., Singh, M. \& Kaumanns, W., eds). Cambridge University Press, Cambridge, p. 237-261.

Neumann, C., Assahad, G., Hammerschmidt, K., Perwitasari-Farajallah, D. \& Engelhardt, E. (2010). Loud calls in male crested macaques, Macaca nigra: a signal of dominance in a tolerant species. - Anim. Behav. 79: 179-183.

O'Brien, T.G. \& Kinnaird, M.F. (1997). Behavior, diet, and movements of the Sulawesi crested black macaque (Macaca nigra). — Int. J. Primatol. 18: 321-351.

Ogawa, H. (1995). Recognition of social relationships in bridging behavior among Tibetan macaques (Macaca thibetana). - Am. J. Primatol. 35: 305-310.

Ostner, J. \& Schulke, O. (2014). The evolution of social bonds in primate males. — Behaviour 151: 871-906. 
Palagi, E., Dall'Olio, S., Demuru, E. \& Stanyon, R. (2014). Exploring the evolutionary foundations of empathy: consolation in monkeys. - Evol. Hum. Behav. 35: 341-349.

Paul, A., Kuester, J. \& Arnemann, J. (1996). The sociobiology of male-infant interactions in Barbary macaques, Macaca sylvanus. - Anim. Behav. 51: 155-170.

Petit, O., Abegg, C. \& Thierry, B. (1997). A comparative study of aggression and conciliation in three cercopithecine monkeys (Macaca fuscata, Macaca nigra, Papio papio). Behaviour. 134: 415-432.

Petit, O. \& Thierry, B. (1994). Reconciliation in a group of black macaques, Macaca nigra. Dodo 30: 89-95.

Preuschoft, S. \& Paul, A. (2000). Dominance, egalitarianism, and stalemate: an experimental approach to male-male competition in Barbary macaques. — In: Primate males: causes and consequences of variation in group composition (Kappeler, P.M., ed.). Cambridge University Press, Cambridge, p. 205-216.

Preuschoft, S., Paul, A. \& Kuester, J. (1998). Dominance styles of female and male Barbary macaques (Macaca sylvanus). — Behav. Ecol. Sociobiol. 135: 731-755.

R Development Core Team (2017). R: a language and environment for statistical computing. - R Foundation for Statistical Computing, Vienna. Available online at http://www. R-project.org/.

Reed, C., Brien, T.G.O. \& Kinnaird, M.F. (1997). Male social behavior and dominance hierarchy in the Sulawesi crested black macaque (Macaca nigra). — Int. J. Primatol. 18: 247-260.

Richter, C., Mevis, L., Malaivijitnond, S., Schülke, O. \& Ostner, J. (2009). Social relationships in free-ranging male Macaca arctoides. — Int. J. Primatol. 30: 625-642.

Riley, E.P., Sagnotti, C., Carosi, M. \& Putu Oka, N. (2014). Socially tolerant relationships among wild male moor macaques (Macaca maura). — Behaviour 151: 1021-1044.

Schino, G., Rosati, L. \& Aureli, F. (1998). Intragroup variation in conciliatory tendencies in captive Japanese macaques. - Behaviour. 135: 897-912.

Schulke, O., Bhagavatula, J., Vigilant, L. \& Ostner, J. (2010). Social bonds enhance reproductive success in male macaques. - Curr. Biol. 20: 2207-2210.

Silk, J.B. (1994). Social relationships of male Bonnet macaques: male bonding in a matrilineal society. - Behaviour 130: 271-291.

Smuts, B.B. \& Watanabe, J.M. (1990). Social relationships and ritualized greetings in adult male baboons. - Int. J. Primatol. 11: 147-172.

Sterck, E.H.M., Watts, D.P. \& Van Schaik, C.P. (1997). The evolution of female social relationships in nonhuman primates. - Behav. Ecol. Sociobiol. 41: 291-309.

Sueur, C., Petit, O., De Marco, A., Jacobs, A.T., Watanabe, K. \& Thierry, B. (2011). A comparative network analysis of social style in macaques. - Anim. Behav. 82: 845-852.

Sugiyama, Y. (1971). Characteristics of the social life of Bonnet macaques (Macaca radiata). - Primates 12: 247-266.

Thierry, B. (1985). Patterns of agonistic interactions in three species of macaque (Macaca mulatta, M. fascicularis, M. tonkeana). - Aggr. Behav. 11: 223-233.

Thierry, B. (1990). The state of equilibrium among agonistic behavior patterns in a group of Japanese macaques (Macaca fuscata). — C. R. Acad. Sci. Série III: Sci. Vie 310: 35-40. 
Thierry, B. (2000). Covariation of conflict management patterns across macaque species. In: Natural conflict resolution (Aureli, F. \& de Waal, F.B.M., eds). University of California Press, Berkeley, CA, p. 106-128.

Thierry, B. (2004). Social epigenesis. - In: Macaque societies: a model for the study of social organization (Thierry, B., Singh, M. \& Kaumanns, W., eds). Cambridge University Press, Cambridge, p. 267-290.

Thierry, B. (2007). Unity in diversity: lessons from macaque societies. — Evol. Anthropol. 16: 224-238.

Thierry, B. (2008). Primate socioecology, the lost dream of ecological determinism. - Evol. Anthropol. 17: 93-96.

Thierry, B. (2013). Identifying constraints in the evolution of primate societies. - Philos. Trans. R. Soc. B. 368: 20120342.

Thierry, B. \& Aureli, F. (2006). Barbary but not barbarian: social relations in a tolerant macaque. - In: Biology and behaviour of Barbary macaques (Hodges, J.K., ed.). Nottingham University Press, Nottingham, p. 1-18.

Thierry, B., Aureli, F., Nunn, C.L., Petit, O., Abegg, C. \& de Waal, F.B.M. (2008). A comparative study of conflict resolution in macaques: insights into the nature of covariation. Anim. Behav. 75: 847-860.

Thierry, B., Bynum, E.L., Baker, S., Kinnaird, M.F. \& Matsumura, S. (2000). The social repertoire of Sulawesi macaques. - Prim. Res. 16: 203-226.

Thierry, B., Demaria, C., Preuschoft, S. \& Desportes, C. (1989). Structural convergence between silent bared-teeth display and relaxed open-mouth display in the Tonkean macaque (Macaca tonkeana). - Folia Primatol. 52: 178-184.

Van Hooff, J.A.R.A.M. (2000). Relationships among non-human primate males: a deductive framework. - In: Primate males: causes and consequences of variation in group composition (Kappeler, P.M., ed.). Cambridge University Press, Cambridge, p. 183-191.

Van Hooff, J.A.R.A.M. \& van Schaik, C.P. (1992). Cooperation in competition: the ecology of primate bonds. - In: Coalitions and alliances in humans and other animals (Harcourt, A.H. \& De Waal, F.B.M., eds). Oxford University Press, New York, NY, p. 357-389.

Van Hooff, J.A.R.A.M. \& Van Schaik, C.P. (1994). Male bonds: affiliative relationships among nonhuman primate males. - Behaviour. 130: 309-337.

Van Schaik, C.P. (1989). The ecology of social relationships amongst female primates. - In: Comparative socioecology (Standen, V. \& Foley, R.A., eds). Blackwell Scientific, Oxford, p. $195-218$.

Van Schaik, C.P. (1996). Social evolution in primates: the role of ecological factors and male behaviour. - Proc. Br. Acad. 88: 9-31.

Van Schaik, C.P. \& van Noordwijk, M.A. (1988). Scramble and contest in feeding competition among female long-tailed macaques (Macaca fascicularis). — Behaviour 105: 77-98.

Veenema, H.C., Das, M. \& Aureli, F. (1994). Methodological improvements for the study of reconciliation. - Behav. Proc. 31: 29-38.

Whitham, J.C. \& Maestripieri, D. (2003). Primate rituals: the function of greetings between male Guinea baboons. — Ethology 109: 847-859. 
BEH (brill2x v1.23) beh3597.tex 2020/04/21 8:43 [research-article] p. 40/41

40

Social style among wild crested macaque males

Wrangham, R.W. (1980). An ecological model of female-bonded primate groups. — Be- 1 haviour 75: 262-300.

Zhang, P. \& Watanabe, K. (2014). Intraspecies variation in dominance style of Macaca 3 fuscata. - Primates 55: 69-79.

Table A1.

Model statistics of linear mixed models comparing male and female crested macaques from groups R1 and PB1.

\begin{tabular}{|c|c|c|c|c|}
\hline Outcome variable & $F_{(1,56)}$ & $p$ & Marginal $R^{2}$ & Conditional $R^{2}$ \\
\hline \multicolumn{5}{|l|}{ Social style measures } \\
\hline CCT & 8.66 & $0.00^{* * *}$ & 0.13 & 0.13 \\
\hline$\%$ Counteraggression & 72.34 & $0.00^{* * * *}$ & 0.57 & 0.57 \\
\hline$\%$ Bite & 10.23 & $0.00^{* * *}$ & 0.15 & 0.23 \\
\hline$\%$ Contact Attack & 9.32 & $0.00^{* * *}$ & 0.15 & 0.21 \\
\hline$\%$ Threat & 6.53 & $0.01^{* *}$ & 0.19 & 0.19 \\
\hline \multicolumn{5}{|c|}{ Approaches within 1 bodylength } \\
\hline$\%$ Positive outcome & 217.76 & $0.00^{* * *}$ & 0.81 & 0.81 \\
\hline$\%$ Negative outcome & 11.11 & $0.00^{* * *}$ & 0.16 & 0.40 \\
\hline$\%$ Neutral outcome & 156.94 & $0.00^{* * *}$ & 0.76 & 0.76 \\
\hline
\end{tabular}

Other measures of social interactions Rate of overall aggression 
